\title{
Photodynamic therapy for neovascular age-related macular degeneration (Review)
}

Wormald R, Evans J, Smeeth L, Henshaw K

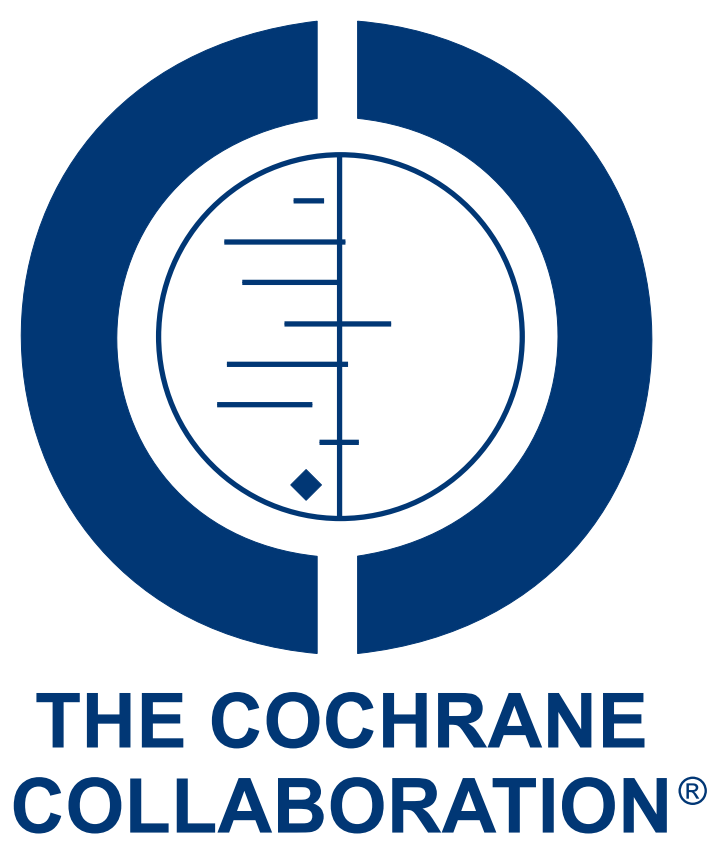

This is a reprint of a Cochrane review, prepared and maintained by The Cochrane Collaboration and published in The Cochrane Library 2003, Issue 2

http://www.thecochranelibrary.com

\section{WILEY}

Photodynamic therapy for neovascular age-related macular degeneration (Review)

Copyright @ 2005 The Cochrane Collaboration. Published by John Wiley \& Sons, Ltd. 
TABLE OF CONTENTS

ABSTRACT . . . . . . . . . . . . . . . . . . . . . . . . . . . . . . . . . . . . 1

SYNOPSIS . . . . . . . . . . . . . . . . . . . . . . . . . . . . . . . . 2

BACKGROUND . . . . . . . . . . . . . . . . . . . . . . . . . . . . . . . . . 2

OBJECTIVES . . . . . . . . . . . . . . . . . . . . . . . . . . . . . . . . . . . . . . . 2

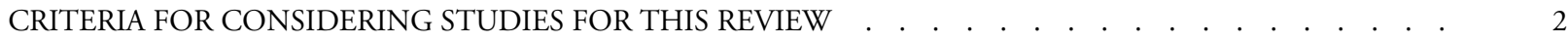

SEARCH STRATEGY FOR IDENTIFICATION OF STUDIES . . . . . . . . . . . . . . . . . . . . . . . . . 3

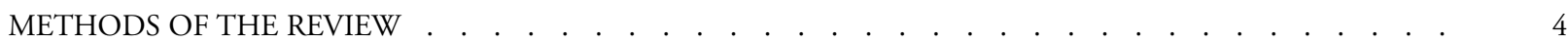

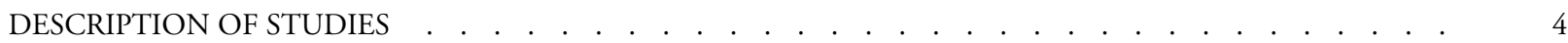

METHODOLOGICAL QUALITY . . . . . . . . . . . . . . . . . . . . . . . . . . . . . . 5

RESULTS . . . . . . . . . . . . . . . . . . . . . . . . . . . . . . . . . 5

DISCUSSION . . . . . . . . . . . . . . . . . . . . . . . . . . . . . . . . . . . . . 6

AUTHORS' CONCLUSIONS . . . . . . . . . . . . . . . . . . . . . . . . . . . . . . . . . . . . . . . . . . 7

POTENTIAL CONFLICT OF INTEREST ．．．．．．．．．．．．．．．．．．．．．．．．．．． . 8

ACKNOWLEDGEMENTS . . . . . . . . . . . . . . . . . . . . . . . . . . . . . . . . 8

SOURCES OF SUPPORT

REFERENCES . . . . . . . . . . . . . . . . . . . . . . . . . . . . . . . . . . . . . 8

TABLES . . . . . . . . . . . . . . . . . . . . . . . . . . . . . . . . . . . 9

Characteristics of included studies . . . . . . . . . . . . . . . . . . . . . . . . . . . . . . . . . . . 9

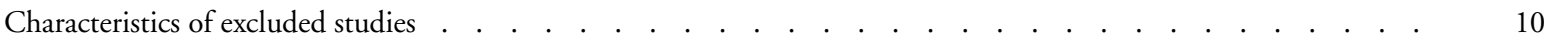

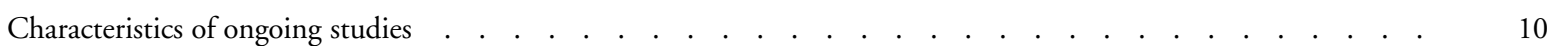

GRAPHS . . . . . . . . . . . . . . . . . . . . . . . . . . . . . . . . . . . . . . . 11

Comparison 01. PHOTODYNAMIC THERAPY WITH VERTEPORFIN VERSUS PLACEBO ．．．． . . 11

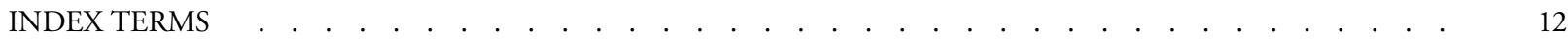

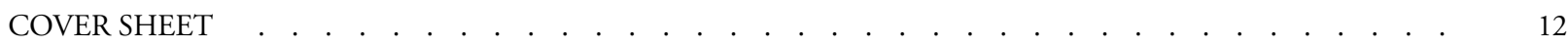

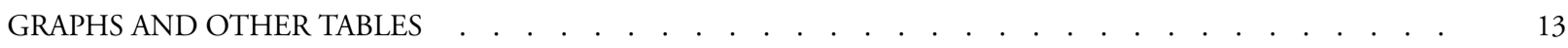

Fig. 1. Comparison 01. PHOTODYNAMIC THERAPY WITH VERTEPORFIN VERSUS PLACEBO. . . . . 13

01 Overall effect: $>=3$ lines lost at 12 mths . . . . . . . . . . . . . . . . . . . . . . . . . . . . 13

Fig. 2. Comparison 01. PHOTODYNAMIC THERAPY WITH VERTEPORFIN VERSUS PLACEBO. . . . . 13

02 Overall effect: $>=3$ lines lost at $24 \mathrm{mths}$. . . . . . . . . . . . . . . . . . . . . . . . . . . 13

Fig. 3. Comparison 01. PHOTODYNAMIC THERAPY WITH VERTEPORFIN VERSUS PLACEBO. . . . . 14

03 Overall effect: $>=6$ lines lost at $12 \mathrm{mths}$. . . . . . . . . . . . . . . . . . . . . . . . . . . . . . . . 14

Fig. 4. Comparison 01. PHOTODYNAMIC THERAPY WITH VERTEPORFIN VERSUS PLACEBO. . . . . . 14

04 Overall effect: $>=6$ lines lost at $24 \mathrm{mths}$. . . . . . . . . . . . . . . . . . . . . . . . . . . . . . . . 14

Fig. 5. Comparison 01. PHOTODYNAMIC THERAPY WITH VERTEPORFIN VERSUS PLACEBO. . . . . . 15

05 Classic CNV subgroups: $>=3$ lines lost at $12 \mathrm{mths}$. . . . . . . . . . . . . . . . . . . . . . . . . . . . . . 15

Fig. 6. Comparison 01. PHOTODYNAMIC THERAPY WITH VERTEPORFIN VERSUS PLACEBO. . . . . . 16

06 Classic CNV subgroups: $>=3$ lines lost at 24 mths . . . . . . . . . . . . . . . . . . . . . . . . . . . . . 16

Fig. 7. Comparison 01. PHOTODYNAMIC THERAPY WITH VERTEPORFIN VERSUS PLACEBO. . . . . . 17

07 Adverse effects: Visual disturbance . . . . . . . . . . . . . . . . . . . . . . . . . . . . . . . . . . . . $\quad 17$

Fig. 8. Comparison 01. PHOTODYNAMIC THERAPY WITH VERTEPORFIN VERSUS PLACEBO. . . . . . 17

08 Adverse effects: Injection site . . . . . . . . . . . . . . . . . . . . . . . . . . . . . . . . . . . . 17

Fig. 9. Comparison 01. PHOTODYNAMIC THERAPY WITH VERTEPORFIN VERSUS PLACEBO. . . . . . 18

09 Adverse effects: Infusion-related back pain c . . . . . . . . . . . . . . . . . . . . . . . . . . . . . . 18

Fig. 10. Comparison 01. PHOTODYNAMIC THERAPY WITH VERTEPORFIN VERSUS PLACEBO. $\quad$ • . $\quad . \quad 18$

10 Adverse effects: Allergic reactions . . . . . . . . . . . . . . . . . . . . . . . . . . . . . . . . . . . . . . 18

Fig. 11. Comparison 01. PHOTODYNAMIC THERAPY WITH VERTEPORFIN VERSUS PLACEBO. . . . 19

11 Adverse effects: Photosensitivity reactions . . . . . . . . . . . . . . . . . . . . . . . . . . . . . . . 19

Photodynamic therapy for neovascular age-related macular degeneration (Review)

Copyright @2005 The Cochrane Collaboration. Published by John Wiley \& Sons, Ltd 


\title{
Photodynamic therapy for neovascular age-related macular degeneration (Review)
}

\author{
Wormald R, Evans J, Smeeth L, Henshaw K
}

This record should be cited as:

Wormald R, Evans J, Smeeth L, Henshaw K. Photodynamic therapy for neovascular age-related macular degeneration. The Cochrane

Database of Systematic Reviews 2003, Issue 2. Art. No.: CD002030. DOI: 10.1002/14651858.CD002030.

This version first published online: 22 April 2003 in Issue 2, 2003.

Date of most recent substantive amendment: 25 February 2003

\begin{abstract}
A B S T R A C T
Background

In neovascular age-related macular degeneration, new vessels grow under the retina, distorting vision and leading to scarring. This is further exacerbated if the blood vessels leak. Photodynamic therapy, originally used in cancer treatment, has been investigated as a way to treat the neovascular membranes without affecting the retina.
\end{abstract}

\section{Objectives}

The aim of this review is to examine the effects of photodynamic therapy in the treatment of neovascular age-related macular degeneration.

\section{Search strategy}

We searched for trials in the Cochrane Central Register of Controlled Trials - CENTRAL (which includes the Cochrane Eyes and Vision Group trials register) on the Cochrane Library (Issue 4 2002), MEDLINE (1966 to November 2002) and EMBASE (1980 to November 2002). We used the Science Citation Index to search for reports that cited relevant study reports. We contacted experts in the field and we searched the reference lists of relevant studies for further trial reports.

\section{Selection criteria}

We included randomised trials of photodynamic therapy in people with choroidal neovascularisation due to age-related macular degeneration.

Data collection and analysis

Two reviewers extracted the data independently. Relative risks were combined using a fixed effect model after testing for heterogeneity using a chi-square test.

\section{Main results}

Two published trials were identified that randomised 948 participants to verteporfin therapy compared to 5\% dextrose in water. Both trials were performed by the same investigators using largely the same clinical centres and funded by manufacturers of verteporfin. Outcome data were available at 12 and 24 months after the first treatment. Participants received on average five treatments over two years. The relative risk of losing three or more lines of visual acuity at 24 months comparing the intervention with the control group was 0.77 (95\% confidence interval 0.69 to 0.87$)$. The relative risk of losing six or more lines of visual acuity at 24 months comparing the intervention with the control group was 0.62 ( $95 \%$ confidence interval 0.50 to 0.76 ). The results at 12 months were similar to those at 24 months.

\section{Authors' conclusions}

Photodynamic therapy in people with choroidal neovascularisation due to age-related macular degeneration is effective in preventing visual loss. Outcomes and potential adverse effects of this treatment should be monitored closely. Further independent trials of Verteporfin are required to establish that the effects seen in this study are consistent and to determine important questions not yet addressed, particularly relating to quality of life and cost.

Photodynamic therapy for neovascular age-related macular degeneration (Review)

Copyright @2005 The Cochrane Collaboration. Published by John Wiley \& Sons, Ltd 


\section{S Y NOP S I S}

Photodynamic therapy may reduce vision loss caused by one type of age-related macular degeneration, but more research is needed

Age-related macular degeneration (AMD) affects the macula, the centre of the retina (the light-sensitive area inside the eye). One type is called 'wet' or neovascular AMD, as new blood vessels develop in the macula. These can leak and scar the eye, causing vision loss. Photodynamic therapy involves injecting chemicals, then radiating light as the chemicals flow through these new blood vessels. This aims to activate the chemicals enough to destroy the vessels, but not enough to hurt the eye. The review found evidence that this may reduce vision loss caused by neovascular AMD, but more research is needed.

\section{B A C K G R O U N D}

Age-related macular degeneration (AMD) is a disease affecting the macula, the central area of the retina. The disease is defined as degeneration of the macula in older people (aged over 50) with no other apparent cause for the degeneration.

There are several signs in the retina that are associated with increasing age and increased risk of developing age-related macular degeneration. These signs, known as age-related maculopathy, include the presence of drusen (yellow spots beneath the retina) and pigmentary disturbance. In general age-related maculopathy is not associated with visual loss. Some people with age-related maculopathy will go on to develop age-related macular degeneration.

There are two main types of AMD. In geographic atrophy (dry) AMD, the retinal pigment epithelium is lost completely in localised areas. In neovascular (wet) AMD, sub-retinal neovascular membranes (new blood vessels) develop beneath the retina. These are associated with scarring of the retina that affects vision. The new vessels can leak causing haemorrhage that leads to larger scars or macular oedema and significant loss of vision. This review is concerned with treatment for neovascular age-related macular degeneration.

Sub-retinal neovascular membranes are defined as classic or occult according to their appearance on fluorescein angiography, in which fluorescent dye is injected intravenously and imaged as it passes through the blood vessels of the eye. Classic membranes are clearly delineated and leak fluorescein uniformly. Occult membranes are often hidden or their extent is hard to delineate, and fluorescein leakage is patchy. It is thought that these two angiographic patterns reflect the different extent to which the vessels have penetrated the retinal pigment epithelium, occult vessels lying underneath the retinal pigment epithelium. Some lesions may have both classic and occult components.

Trials have shown that early laser photocoagulation of classic extrafoveal membranes (those not directly underneath the fovea at the centre of the macula) could delay the loss of vision in a small number of patients (MPS 1994). However, most patients present with subfoveal membranes, and whilst photocoagulation can limit the extent of the subsequent visual loss, it causes immediate loss of central vision due to the concurrent destruction of the overlying retina.

Photodynamic therapy, originally used in the treatment of cancer, has been investigated as a way to treat the neovascular membranes without affecting the retina. Photoreactive chemicals are injected into the patient and irradiated with light as they pass through the neovascular membranes. This light is strong enough to activate the chemicals, causing them to emit free radicals that destroy the blood vessels, but is not strong enough to cause damage to the overlying retina.

\section{O B J E C T I VES}

The aim of this review is to examine the effects of photodynamic therapy in the treatment of neovascular age-related macular degeneration.

\section{CRITERIA FOR CONSIDERING STUDIES FOR THIS REVIEW}

\section{Types of studies}

We included randomised controlled trials.

\section{Types of participants}

We included trials in which participants were people with neovascular age-related macular degeneration as defined by the study investigators.

\section{Types of intervention}

We included any study in which photodynamic therapy was compared to another treatment, placebo or no treatment.

\section{Types of outcome measures}

The primary outcome for this review is prevention of visual loss. Any well-defined outcome based on visual acuity was used depending on the way in which authors presented trial data. Other validated measures of visual loss, such as contrast sensitivity, were used where available.

The secondary outcomes for this review are: 
- new vessel growth,

- quality of life measures - any validated measurement scale which aims to measure the impact of visual function loss on quality of life of participants,

- any adverse outcomes as reported in trials.

\section{SEARCH STRATEGY FOR IDENTIFICATION OF STUDIES}

See: Eyes and Vision Group search strategy

Trials were identified from the Cochrane Central Register of Controlled Trials - CENTRAL (which contains the Cochrane Eyes and Vision Group trials register) on the Cochrane Library, MEDLINE and EMBASE.

The following strategy was used to search CENTRAL Issue 4 2002:

\#1 MACULAR-DEGENERATION:ME

\#2 RETINAL-DEGENERATION:ME

\#3 NEOVASCULARIZATION-PATHOLOGIC*:ME

\#4 (((((MACULA or MACULAR) or RETINA) or RETINAL)

or CHOROID) or CHOROIDAL) near (DEGENERATION

or NEOVASCULARIZATION))

\#5 MACULOPATHY

$\# 6((((\# 1$ or $\# 2)$ or \#3) or \#4) or \#5)

\#7 PHOTOCHEMOTHERAPY*:ME

\#8 PHOTOSENSITIZING-AGENTS*:ME

\#9 ((()(PHOTOSENSITIZING or PHOTOSENSITISING) or PHOTODYNAMIC) or PDT) or VERTEPORFIN) or VISUDYNE)

\#10 ((\#7 or \#8) or \#9)

$\# 11$ (\#6 and \#10)

The following was used to search MEDLINE on SilverPlatter to November 2002:

\#1 "MACULAR-DEGENERATION"/ all subheadings \#2 "RETINAL-DEGENERATION"/ all subheadings \#3 “CHOROIDAL-NEOVASCULARIZATION"/ all subheadings

\#4 ((MACUL* or RETINA* or CHOROID*) near (DEGENER* ${ }^{*}$ or NEOVASC*)) in TI,AB

\#5 MACULOPATHY in TI,AB

$\# 6 \# 1$ or $\# 2$ or $\# 3$ or $\# 4$ or \#5

\#7 explode "PHOTOCHEMOTHERAPY"/ all subheadings

\#8 explode "PHOTOSENSITIZING-AGENTS"/ all

subheadings

\#9 (PHOTOSENSITI?ING?AGENTS or 'PHOTOSENSITI?ING AGENTS' or PORPHYRIN* or BENZOPORPHYRIN) in NM,TI,AB \#10 (PHOTODYNAMIC or PDT) in TI,AB
\#11 VERTEPORFIN or VISUDYNE in TI,AB

$\# 12$ \#7 or \#8 or \#9 or \#10 or \#11

$\# 13 \# 6$ and \#12

To identify randomised controlled trials, this search was combined with the Cochrane Highly Sensitive Search Strategy phases one and two as contained in the Cochrane Reviewers' Handbook (Clarke 2000).

The following strategy was used to search EMBASE on SilverPlatter to November 2002:

\#1 explode "RETINA-MACULA-DEGENERATION"/ all subheadings

\#2 "RETINA-DEGENERATION"/ all subheadings

\#3 "NEOVASCULARIZATION-(PATHOLOGY)"/ all

subheadings

\#4 “SUBRETINAL-NEOVASCULARIZATION"/ all

subheadings

\#5 ((MACUL* or RETINA* or CHOROID*) near

(DEGENER* or NEOVASC*)) in TI,AB

\#6 MACULOPATHY in TI,AB

$\# 7 \# 1$ or $\# 2$ or \#3 or \#4 or \#5 or \#6

\#8 "PHOTODYNAMIC-THERAPY"/ all subheadings

\#9 explode "PHOTOSENSITIZING-AGENT"/ all subheadings \#10 (PHOTODYNAMIC or PDT) in TI,AB

\#11 (PHOTOSENSITI?ING AGENT* or VERTEPORFIN or VISUDYNE) in RN,TI,AB

$\# 12$ \#8 or \#9 or \#10 or \#11

$\# 13 \# 7$ and \#12

To identify randomised controlled trials, this search was combined with the following search:

\#1 "RANDOMIZED-CONTROLLED-TRIAL"/ all subheadings

\#2 "RANDOMIZATION"/ all subheadings

\#3 "CONTROLLED-STUDY"/ all subheadings

\#4 "MULTICENTER-STUDY"/ all subheadings

\#5 "PHASE-3-CLINICAL-TRIAL"/ all subheadings

\#6 "PHASE-4-CLINICAL-TRIAL"/ all subheadings

\#7 "DOUBLE-BLIND-PROCEDURE"/ all subheadings

\#8 "SINGLE-BLIND-PROCEDURE"/ all subheadings

$\# 9 \# 1$ or $\# 2$ or $\# 3$ or $\# 4$ or $\# 5$ or $\# 6$ or $\# 7$ or \#8

\#10 (RANDOM* $^{*}$ or CROSS?OVER* ${ }^{*}$ or FACTORIAL* or PLACEBO* $^{*}$ or VOLUNTEER*) in TI,AB

\#11 (SINGL* or DOUBL* or TREBL* or TRIPL*) near (BLIND* or MASK*) in TI,AB

\#12 \#9 or \#10 or \#11

\#13 HUMAN in DER

\#14 (ANIMAL or NONHUMAN) in DER

\#15 \#13 and \#14

\#16 \#14 not \#15

\#17 \#12 not \#16 
We used the Science Citation Index to search for reports that cited relevant study reports. We contacted experts in the field for information about further trials, and we searched the reference lists of relevant studies for further trial reports.

\section{METHODSOF THE REVIEW}

\section{Selection of trials}

Two reviewers independently scanned the titles and abstracts resulting from the electronic searches. We obtained full copies of all potentially or definitely relevant articles. Two reviewers assessed the full copies according to the 'Criteria for considering studies for this review'. Only articles meeting these criteria were assessed for quality.

Assessment of methodological quality

Two reviewers independently assessed study quality according to methods set out in Section 6 of the Cochrane Reviewers' Handbook. Reviewers were not masked to any trial details during the assessment. Four parameters of quality were considered: allocation concealment and method of allocation to treatment, masking of providers and recipients of care, masking of outcome assessment, and completeness of follow-up. Each parameter of trial quality was graded: A - adequate; B - unclear; C - inadequate. Disagreement between the reviewers on assessments was resolved by discussion. We contacted the trial authors for clarification on any parameter graded B - unclear, and we excluded any trial scoring $\mathrm{C}$ - inadequate on allocation concealment.

Data collection

Two reviewers independently extracted data using a form developed by the Cochrane Eyes and Vision Group (available from the editorial base). We resolved discrepancies by discussion. Two reviewers independently entered data into RevMan 4.1 and we checked any inconsistencies between the two against the study report.

Data synthesis

Our original data analysis plan was to summarise data from studies collecting similar outcome measures with similar follow-up times using the Peto method, after testing for heterogeneity between trial results using a standard chi-square test. The main outcome analysed, loss of three or more lines of visual acuity at 12 and 24 months follow-up, occurred relatively frequently in the trial cohort. The odds ratio, therefore, does not approximate to the relative risk. We present relative risks in this review. We planned to conduct sensitivity analyses to determine the effect of excluding studies given a grade of $\mathrm{C}$ - inadequate on any parameter of quality, but to date this has not been necessary.

\section{DESCRIPTIONOFSTUDIES}

The original electronic searches identified 76 reports. We found one randomised controlled trial (TAP 1999). Since the searches were updated in February 2001, May 2002 and January 2003, one further study has been identified and is included in this review (VIP 2001).

The TAP 1999 study was a multicentre study investigating the safety and effectiveness of verteporfin (Visudyne; CIBA Vision Corp, USA). It was conducted in 22 ophthalmology practices in Europe and North America. Participants were people with subfoveal choroidal neovascularisation (CNV) caused by age-related macular degeneration. The majority of participants were white (98\%) with a mean age of 75 years. The VIP 2001 study was very similar to the TAP 1999 study. It was conducted in 28 practices, most of whom had also participated in the TAP 1999 study. As for the TAP 1999 study, the majority of participants were white $(98 \%)$ with a mean age of 75 years.

In both trials, verteporfin (six milligrams per square metre of body surface area) was compared to placebo (5\% dextrose in water) administered via intravenous infusion of 30 millilitres over 10 minutes. This was followed after 15 minutes by application of 83 seconds of laser light at $689 \mathrm{~nm}$ delivered 50 joules/square centimetre $\left(\mathrm{cm}^{2}\right)$ at an intensity of $600 \mathrm{~mW} / \mathrm{cm}^{2}$ using a spot size with a diameter 1000 microns larger than the greatest linear dimension of the CNV lesion.

Participants in the TAP 1999 trial were reviewed every three months when visual acuity was measured and repeat fluorescein angiography performed. If the trial surgeon judged a recurrence of the membrane to be present or a persistence of the previous lesion, then repeat treatment was undertaken. In the phase one and two studies, it was concluded that up to five treatments were necessary to stabilise the situation (Miller 1999; Schmidt-Erfurth 1999). In the first year, a mean of 3.4 treatments were delivered to the treatment group and 3.7 to the control group. In the second year, a mean of 2.2 treatments were delivered to the treatment group and 2.8 to the controls group.

Visual acuity was measured in the VIP 2001 trial at 12 and 24 months. The report of the study did not indicate the mean number of treatments delivered for all participants. However, in the subgroup with occult CNV (76\% of all participants) 3.1 treatments were given in the treatment group and 3.5 in the control group. In the second year, 1.8 and 2.4 treatments were given in the verteporfin and control groups respectively.

TAP 1999 was originally devised as two concurrent trials in order to comply with regulatory agency requirements. The study protocols were identical. Ten of the clinical centres were assigned to study A and 12 to study B. As the results of the trials were similar and the investigators analysed and presented the data as one trial, we have also assessed it as one trial. 


\section{METHODOLOGICAL QUALITY}

Both TAP 1999 and VIP 2001 were high quality studies with a very similar study design.

Allocation of treatment group was by opaque serially numbered sealed envelopes and was stratified by clinical centre. The baseline characteristics of the participants by treatment group were published. The groups were well balanced with respect to a variety of demographic and clinical variables. Only one eye per person was treated.

Reasonable attempts were made to mask the ophthalmologist, participant, vision examiner and Photograph Reading Center personnel to the treatment assigned. As verteporfin and placebo were different colours (green versus colourless), the solutions and the intravenous tubing were covered with foil. The fundus appearance does not change during treatment to indicate whether verteporfin or placebo had been infused. There is no other physical evidence of treatment as verteporfin dye is excreted in the faeces and does not cause any colour change, and does not alter the colour of the skin or urine. It was therefore unlikely that participants were aware of their treatment status. In TAP 1999 the study investigators reported two instances where the participants were unmasked, and four cases where the ophthalmologists were unmasked, having noted a green solution.

Rates of follow-up were high in both studies. In TAP 1999 94\% were seen at 12 months and $87 \%$ at 24 months. Follow-up was similar between the two treatment groups. The analysis was intention-to-treat and subgroup analyses were planned a priori (Bressler $\mathrm{N}$, personal communication). In VIP $200193 \%$ were seen at 12 months and $86 \%$ at 24 months. All participants were included in the analyses and missing values were imputed using the method of last observation carried forward.

\section{R E S U L T S}

The realistic aim of photodynamic therapy is to slow progression of age-related macular degeneration, not to produce normal vision. Outcomes are therefore expressed as risks of a poor outcome, rather than as improvements in vision. All results are based on the comparison of people randomised to receive verteporfin with those randomised to receive placebo (control).

\section{OVERALL ANALYSIS}

Loss of three or more lines of visual acuity

A total of 948 patients from TAP 1999 and VIP 2001 studies were included in the meta-analysis. At 12 months, the pooled relative risk of losing three or more lines of visual acuity was 0.80 (95\% confidence interval (CI) 0.70 to 0.91 ). The relative risk reduction was therefore 0.20 (95\% CI 0.09 to 0.30 ). This analysis was done using a fixed effect model. A random effects model gave a non- significant result, largely because it placed more weight on the VIP study (pooled relative risk 0.82 (95\% CI 0.64 to 1.04 ).

At 24 months, the pooled relative risk was 0.77 (95\% CI 0.69 to $0.87)$ and the relative risk reduction was therefore 0.23 (95\% CI

0.13 to 0.31 ). The random effects model gave a similar result.

Loss of six or more lines of visual acuity

At 12 months, the relative risk of losing six or more lines of visual acuity was 0.62 (95\% CI 0.44 to 0.87 ) (TAP 1999 study only, data not reported for VIP 2001 study). The relative risk reduction was therefore 0.38 ( $95 \%$ CI 0.13 to 0.56 ). At 24 months, the pooled relative risk was 0.62 (95\% CI 0.50 to 0.76$)$ and the relative risk reduction was therefore 0.38 ( $95 \%$ CI 0.24 to 0.50 ).

Mean number of lines lost In the TAP 1999 the mean number of lines of vision lost at 12 months was 2.2 in the intervention group and 3.5 in the control group. The difference was 1.3 with fewer lines lost in the intervention group. The $\mathrm{P}$ value for the difference in the mean number of lines lost was reported as $\mathrm{P}<0.001$ (Wilcoxon rank sum test). At 24 months, the mean number of lines of vision lost was 2.7 in the intervention group and 3.9 in the control group, a difference of 1.2 lines $(\mathrm{P}<0.001)$.

The standard deviations for the mean numbers of lines lost were not reported and we therefore could not calculate confidence intervals.

Data on mean number of lines lost for the whole VIP 2001 study group was not reported.

\section{SUBGROUP ANALYSES}

Subgroup data are available only for the outcome 'loss of three or more lines of visual acuity' in the TAP 1999 study but for both outcomes (loss of three lines and loss of six lines) in the VIP 2001 study.

Evidence of occult choroidal neovascularisation In the TAP 1999 study the relative risks of losing three or more lines of visual acuity at 12 months were 0.90 if occult choroidal neovascularisation (CNV) was present $(95 \%$ CI 0.73 to 1.11$)$ and 0.34 if occult CNV was absent (95\% CI 0.22 to 0.51 ). At 24 months, the relative risks were 0.88 (95\% CI 0.74 to 1.04$)$ and 0.42 (95\% CI 0.30 to 0.60 ) respectively.

The test for effect modification between these two subgroups was significant. Neither the $95 \%$ confidence intervals, nor the $99 \%$ confidence intervals, for these two subgroups overlap.

Lesion area composed of classic choroidal neovascularisation In the TAP 1999 study, the proportion of the lesion comprised of classic $\mathrm{CNV}$ was estimated as $0 \%$; greater than $0 \%$ but less than $50 \%$; greater than $50 \%$. The proportion was unknown in four participants (three in the treatment group and one in the control group). The subgroup analyses were therefore based on a total of 399 eyes. 
In the VIP 2001 study, the majority of the participants (76\%) had "occult with no classic CNV". An additional 56 eyes had some classic CNV (less than $50 \%$ but greater than $0 \%$ as above). Only 19 eyes had predominantly classic CNV.

The pooled relative risks for losing three or more lines of visual acuity at 12 months for the group with $0 \% \mathrm{CNV}$ was 0.84 (95\% CI 0.68 to 1.04 ). Results for three or more lines lost at 12 months were not reported for the other two subgroups in the VIP 2001 study. The results for the TAP 1999 study were as follows. The relative risk for losing three or more lines of visual acuity at 12 months in people with $0 \%$ but less than $50 \% \mathrm{CNV}$ was $0.99(95 \%$ CI 0.76 to 1.29$)$ and 0.54 for greater than $50 \%$ (95\% CI 0.40 to $0.71)$.

At 24 months the pooled relative risks for losing three or more lines of visual acuity were: 0.77 (95\% CI 0.64 to 0.92$), 0.93$ (95\% CI 0.77 to 1.14$)$ and 0.60 (95\% CI 0.48 to 0.75$)$ respectively.

These results suggest there was a reduction in the risk of loss of vision when classic CNV was absent or when greater than $50 \%$ of the lesion was comprised of classic CNV. However there was very little reduction in risk when between $0 \%$ and $50 \%$ of the lesion was comprised of classic CNV. However the test for effect modification between these three subgroups was not statistically significant $(\mathrm{p}=0.066)$.

\section{NUMBERS NEEDED TO TREAT}

We calculated the numbers needed to treat (NNTs) to prevent one person losing three or more lines and, where possible, one person losing six or more lines of vision. These NNTs are derived from the study population, that is, people with subfoveal CNV and a baseline visual acuity of between 20/40 and 20/200 with approximately 5 treatments over two years.

The NNT to prevent one person losing three or more lines of vision at 24 months was 7.1 (95\% CI 4.8 to 12.5 ). The NNT to prevent one person losing six or more lines of vision at 24 months was 7.1 (95\% CI 5.0 to 12.5$)$.

\section{ADVERSE EFFECTS}

Reports of visual disturbance (reports of "abormal vision", "decreased vision" and visual field defect) occurred in one in every four people taking part in the TAP 1999 and VIP 2001 studies. This is perhaps unsurprising as participants had neovascular AMD. However, people treated with verteporfin were more likely to report visual disturbance (pooled relative risk 1.61, 95\% CI 1.24 to 2.09). Presumably this visual disturbance must have been reasonably transient as visual outcomes at 12 and 24 months were better in the treatment group. $2.4 \%$ of people treated with verteporfin experienced infusion-related back pain and $2.4 \%$ had photosensitivity reactions. Problems with the injection site occurred in $13.1 \%$ of people treated with verteporfin compared to $5.6 \%$ people in the control group. Few allergic reactions were seen and these were equally likely in treatment and control groups.

\section{I S C USS I O N}

The absence to date of any effective treatment for neovascular agerelated macular degeneration (except for the few in whom laser photocoagulation works) means that there will be intense interest in photodynamic therapy for the many millions of sufferers of the disease worldwide. Unfortunately, photodynamic therapy, like photocoagulation, can only be effective during the proliferative stage of the disease while the neovascular process is active. It cannot have any effect once sight is lost and the scarring process is complete. Therefore, like so many other degenerative processes of the neuroretina, nothing can be done to restore function once the damage is done. Most sufferers of the condition have established sight loss and, for these, the publicity surrounding the launch of Visudyne (verteporfin) will have raised false hopes. However, this review indicates that for people with active neovascular disease, photodynamic therapy can prevent vision loss.

A key question is how long the effect of treatment will last and whether repeated treatments would be required in the longer term. This review indicates that treatment benefits last for at least two years. An open-label extension of the TAP 1999 study indicated that vision outcomes remained relatively stable from 24 to 48 months(TAP 2002).

Another important issue is how many presenting patients will benefit from photodynamic therapy. In addition to the problem of accessing specialist services in time, there is the question of the proportion of lesions that will actually be treatable. The evidence reported here clearly suggests that purely classic neovascular membranes do well. Subgroup analysis of the TAP 1999 study suggested that photodynamic therapy is not effective when occult CNV is present. Occult vessels mean that the extent of the membrane cannot be clearly defined and so it is not surprising that treatment is found to be less effective because the laser cannot be aimed at the entire membrane. However, the VIP 2001 study recruited mostly patients with occult neovascularisation and demonstrated a treatment benefit of photodynamic therapy at 12 and 24 months. Pooled analysis of the TAP 1999 and VIP 2001 studies in this review showed no statistically significant difference in treatment effects in subgroups defined by the presence or absence of classic $\mathrm{CNV}$.

We are not told in the available reports the extent to which clinicians and indeed the trial Photograph Reading Center personnel were able to agree about the subgroup classification of classic or occult lesions. It is likely that there is much variation in opinion on this. The necessary skill to report on fluorescein angiograms and recognise different lesion types is highly refined. Most experts assert that stereo images are required to be able to locate the position in depth of staining or fluorescein leaks. Stereophotography requires either a dedicated camera equipped to take simultaneous stereo images or a skilled photographer who takes sequential im- 
ages slightly laterally displaced from one another, providing a nonsimultaneous or pseudo-stereo image.

The natural history of the growth of sub-retinal membranes varies from individual to individual. They may be aggressive and rapidly growing or indolent. This is the kind of individual factor that will influence the likelihood of a patient being in a position to benefit from this treatment. The trial report does not comment on the proportion of participants presenting to the trial centres that had treatable lesions. The verbal estimate from one trialist was approximately $25 \%$, and of another expert, between $5 \%$ and $7 \%$. This is of crucial importance in estimating the impact of this new treatment on health care budgets.

Age-related macular degeneration is a bilateral disease although one eye is usually affected before the other. With a lesion present in one eye, the annual cumulative incidence of a lesion in the second eye is estimated to be about $15 \%$. Clinicians now commonly advise patients with a lesion in one eye to be watchful for the onset of symptoms in the second eye, and to present as soon as those symptoms are noticed to improve the chances of catching the lesion in the second eye in time. This often entails the provision of an Amsler grid, a simple chart on which a number of gridlines are printed around a central fixation spot. The patient is instructed to examine the grid and to look for focal distortion of the lines in the grid which would indicate local elevation of the retina as a result of the growth of an underlying membrane. This strategy offers the best hope of saving sight with this new treatment at least in places where access to a qualified ophthalmologist can be slow.

It should also be recalled that this treatment does not restore sight but rather, prevents further deterioration. Sustaining numerous assessments which involve relative invasive treatments may have an adverse effect on the patient. Without patient orientated outcomes in this trial, we cannot comment on the patient's perspective on the experience of Visudyne therapy. It is likely that in most cases, especially where loss of sight of the second eye is threatened, patients will be willing to undergo all the necessary interventions, even when the probability of success is small.

Adverse effects occurred infrequently with the exception of the rather vague "visual disturbance" which affected more people in the verteporfin group compared to the control group. However, this was not reflected in the visual acuity outcomes. Infusionrelated back pain occurred in $2.4 \%$ which is substantially lower than in some other studies. For example, in a series of 250 people treated with verteporfin $9.6 \%$ experienced verteporfin associated pain, most of which was back pain (Borodoker 2002).

The trials included in this review appear to have been performed to high standards and were closely supervised by the Food and Drugs Administration of the USA. Both trials were sponsored by the manufacturers of the drug (CIBA Vision \& Novartis Ophthalmics) and declared potential conflicts of interest exist for a number of the trialists who hold interests in the manufacturer of the laser technology. This makes detailed scrutiny of reports of the trial essential. Of concern are the numerous protocol revisions that were registered with the Institutional Review Bodies throughout the study and after completion of follow-up. Although we have not yet had access to the main protocol or to the revisions, a CIBA representative has assured us that the changes were not substantive and, in particular, that there were no changes to the a priori determinants of the primary outcomes.

\section{A U THORS' CONCLUSIONS}

\section{Implications for practice}

This review provides evidence that photodynamic therapy in people with classic and occult choroidal neovascularisation due to agerelated macular degeneration is effective in preventing visual loss. Approximately seven people need to be treated with approximately five treatments over two years to prevent one person losing three or more lines of visual acuity.

Two trials were included in this review. Both trials were performed by the same investigators using largely the same clinical centres and funded by manufacturers of verteporfin. As for all new technology, outcomes and potential adverse effects need to be monitored when introduced into clinical practice.

There are major implications for health services, both in terms of potential expenditure and organisation, if photodynamic therapy is to be introduced. Where referral to an ophthalmologist is through a primary care network, facilities for the recognition of this condition in its early stages are needed. There is potential for an enormous increase in referral of people with early age-related maculopathy for assessment, in case an early treatable lesion is present. This could swamp already overstretched facilities at the secondary care level. Extra resources will be required at the secondary care level to manage increased referrals, for the necessary technology to diagnose treatable lesions and to deliver treatment.

\section{Implications for research}

Two trials were included in this review. Both trials were performed by the same investigators using largely the same clinical centres and funded by manufacturers of verteporfin.

Further independent trials of verteporfin are required to establish that the effects seen in this study are consistent and to determine important questions not yet addressed - particularly relating to quality of life and cost. Descriptive epidemiology on the population at risk and the numbers likely to benefit is essential to estimate the impact of this new treatment on health service resources. We need to establish how people in need of treatment can access it in time. Surveillance for possible rare but severe adverse effects will be required. 


\section{POTENTIAL CONFLICTOF INTERES T}

None known.

\section{ACKNOWLEDGEMENTS}

The Cochrane Eyes and Vision Group developed and executed the electronic searches. We would like to thank Neil Bressler, Simon Harding and Javed Bhatti (CIBA Vision) for providing information about the TAP study. Usha Chakravarthy (Queens University, Belfast) and Bob Thompson (Macular Disease Society) provided useful comments on the review.

\section{SOURCES OF SUPPORT}

External sources of support

- No sources of support supplied

Internal sources of support

- Moorfields Eye Hospital NHS Trust UK

\section{R E F E R E N C E S}

\section{References to studies included in this review}

TAP 1999 \{published and unpublished data\}

Rubin GS, Bressler NM, the Treatment of Age-Related Macular Degeneration with Photodynamic Therapy (TAP) Study Group. Effects of verteporfin therapy on contrast sensivity: results from the treatment of age-related macular degeneration with photodynamic therapy (TAP) investigation - TAP report no. 4. Retina 2002;22(5):536544

Treatment of Age-Related Macular Degeneration with Photodynamic Therapy (TAP) Study Group. Verteporfin therapy for subfoveal choroidal neovascularization in age-related macular degeneration: three-year results of an open-label extension of 2 randomized clinical trials - TAP report no 5. Archives of Ophthalmology 2002;120 (10):1307-1314. 12365909.

* Treatment of Age-related Macular Degeneration With Photodynamic Therapy (TAP) Study Group. Photodynamic therapy of subfoveal choroidal neovascularization in age-related macular degeneration with verteporfin: One-year results of 2 randomized clinical trials - TAP report. Archives of Ophthalmology 1999;117(10):1329-1345. 10532441

Treatment of Age-related Macular Degeneration With Photodynamic Therapy (TAP) Study Group. Photodynamic therapy of subfoveal choroidal neovascularization in age-related macular degeneration with verteporfin: Two-year results of 2 randomized clinical trials
- TAP report 2. Archives of Ophthalmology 2001;119(2):198-207. 11176980

VIP 2001 \{published data only\}

Bressler NM. Verteporfin therapy of subfoveal choroidal neovascularization in age-related macular degeneration: two-year results of a randomized clinical trial including lesions with occult with no classic choroidal neovascularization - Verteporfin In Photodynamic Therapy Report 2. American Journal of Ophthalmology 2002;133(1):168169. 11755871.

* Verteporfin in Photodynamic Therapy Study Group. Verteporfin therapy of subfoveal choroidal neovascularization in age-related macular degeneration: two-year results of a randomized clinical trial including lesions with occult with no classic choroidal neovascularization - Verteporfin in Photodynamic Therapy Report 2. American Journal of Ophthalmology 2001;131(5):541-560. 11336929.

\section{References to studies excluded from this review}

\section{Schmidt-Erfurth 1999}

Schmidt-Erfurth U, Miller JW, Sickenberg M, Laqua H, Barbazetto I, Gragoudas ES, et al. Photodynamic therapy with verteporfin for choroidal neovascularisation caused by age-related macular degeneration. Results of retreatment in a phase 1 and 2 study. Archives of Ophthalmology 1999;117(9):1177-1187. 10496389. 


\section{References to ongoing studies}

ADD-V

Addition of an anti-inflammatory called Voltaren Ophthalmic ${ }^{\circledR}$.

Ongoing study Starting date of trial not provided. Contact author for more information.

Japan

Visudyne for CNV due to AMD. Ongoing study Results expected at end 2003.

\section{VALIO}

Altered light treatment using delayed light after Visudyne in occult AMD. Ongoing study Starting date of trial not provided. Contact author for more information.

VER

Visudyne in Early Retreatment Phase IIIB clinical trial. Ongoing study Results expected at end 2003.

VIM

Visudyne in Minimally Classic study. Ongoing study Starting date of trial not provided. Contact author for more information.

VIO

Visudyne therapy in Occult Phase III trial. Ongoing study Starting date of trial not provided. Contact author for more information.

\section{Additional references}

Borodoker 2002

Borodoker N, Spaide RF, Maranan L, Murray J, Freund KB, Slakter

JS, et al. Verteporfin infusion-associated pain. American Journal of Ophthalmology 2002;133(2):211-214. 11812424.

\section{Clarke 2000}

Clarke M, Oxman AD, editors. Cochrane Reviewers' Handbook 4.1 [updated June 2000]. Review Manager (RevMan) [Computer pro- gram]. Version 4.1. Oxford, England: The Cochrane Collaboration, 2000.

Fine 1999

Fine SL. Photodynamic therapy with verteporfin is effective for selected patients with neovascular age-related macular degeneration. Archives of Ophthalmology 1999;117(10):1400-1402. 10532450.

\section{Miller 1999}

Miller JW, Schmidt-Erfurth U, Sickenberg M, Pournaras CJ, Laqua $\mathrm{H}$, Barbazetto I, et al. Photodynamic therapy with verteporfin for choroidal neovascularisation caused by age-related macular degeneration. Results of a single treatment in a phase 1 and 2 study. Archives of Ophthalmology 1999;117(9):1161-1173. 10496388.

MPS 1994

Macular photocoagulation study group. Laser photocoagulation for juxtafoveal choroidal neovascularization: five year results from randomized clinical trials. Archives of Ophthalmology 1994;112(4):500509.7512336.

TAP 2002

Treatment of Age-Related Macular Degeneration with Photodynamic Therapy (TAP) Study Group. Verteporfin therapy for subfoveal choroidal neovascularization in age-related macular degeneration: three-year results of an open-label extension of 2 randomized clinical trials - TAP report no 5. Archives of Ophthalmology 2002;120 (10):1307-1314. 12365909.

Yusuf 1991

Yusuf S, Wittes J, Probstfield J, Tyroler HA. Analysis and interpretation of treatment effects in subgroups of patients in randomized clinical trials. JAMA 1991;266(1):93-98. 2046134.

* Indicates the major publication for the study

T A B LE S

\section{Characteristics of included studies}

\begin{tabular}{ll} 
Study & TAP 1999 \\
\hline Methods & Randomised controlled trial: one eye per patient was randomised in a 2:1 (treatment:control) ratio \\
\hline Participants & $\begin{array}{l}\text { 609 people with subfoveal CNV lesions caused by AMD with evidence of classic CNV and best corrected } \\
\text { acuity of approximately 20/40 to 20/200 }\end{array}$ \\
\hline Interventions & $\begin{array}{l}\text { Photodynamic therapy following verteporfin injection versus photodynamic therapy following intravenous } \\
5 \% \text { dextrose }\end{array}$ \\
\hline Outcomes & Visual acuity at 12 and 24 months \\
\hline Notes & A \\
\hline Allocation concealment & \\
\hline
\end{tabular}

Study 2001

Methods Randomised controlled trial: one eye per patient was enrolled. Randomisation in sealed envelopes stratified by clinical centre.

Photodynamic therapy for neovascular age-related macular degeneration (Review)

Copyright $@ 2005$ The Cochrane Collaboration. Published by John Wiley \& Sons, Ltd 


\section{Characteristics of included studies (Continued)}

Participants

Interventions

Outcomes

Notes

Allocation concealment A

AMD - age-related macular degeneration

$\mathrm{CNV}$ - choroidal neovascularisation

\section{Characteristics of excluded studies}

Schmidt-Erfurth 1999 Non randomised open-label phase I and II trial

Schmidt-Erfurth 1990 Non randomised open-label phase I and II trial
339 people with subfoveal CNV caused by AMD

Photodynamic therapy following verteporfin injection versus photodynamic therapy following intravenous $5 \%$ dextrose

Visual acuity at 12 and 24 months

Secondary outcomes include contrast sensitivity and changes in angiographic outcomes

Randomised 2:1 to verteporfin treatment

\section{Characteristics of ongoing studies}

\begin{tabular}{|c|c|}
\hline Study & DD-V \\
\hline Trial name or title $A$ & Iddition of an anti-inflammatory called Voltaren Ophthalmic $®$ \\
\hline Participants & \\
\hline Interventions & \\
\hline Outcomes & \\
\hline Starting date & \\
\hline Contact information & \\
\hline Notes & \\
\hline Study & Japan \\
\hline Trial name or title & Visudyne for CNV due to AMD \\
\hline Participants & \\
\hline Interventions & \\
\hline Outcomes & \\
\hline Starting date & Results expected at end 2003 \\
\hline Contact information & Nic Gwatkin, Head of Marketing, Novartis Ophthalmics \\
\hline Notes & \\
\hline Study & VALIO \\
\hline Trial name or title & Altered light treatment using delayed light after Visudyne in occult AMD \\
\hline Participants & \\
\hline Interventions & \\
\hline Outcomes & \\
\hline Starting date & \\
\hline Contact information & Nic Gwatkin, Head of Marketing, Novartis Ophthalmics \\
\hline Notes & \\
\hline
\end{tabular}




\title{
Characteristics of ongoing studies (Continued)
}

\begin{tabular}{|c|c|}
\hline Study & VER \\
\hline Trial name or title & Visudyne in Early Retreatment Phase IIIB clinical trial \\
\hline Participants & $\begin{array}{l}\text { People with predominantly classic CNV } \\
321 \text { people at } 31 \text { sites enrolled }\end{array}$ \\
\hline Interventions & Visudyne therapy every 3 months (standard) vs more frequent regiment \\
\hline \multicolumn{2}{|l|}{ Outcomes } \\
\hline Starting date & Results expected at end 2003 \\
\hline Contact information & Nic Gwatkin, Head of Marketing, Novartis Ophthalmics \\
\hline \multicolumn{2}{|l|}{ Notes } \\
\hline Study & VIM \\
\hline Trial name or title & Visudyne in Minimally Classic study \\
\hline \multicolumn{2}{|l|}{ Participants } \\
\hline Interventions & Visudyne therapy vs visudyne therapy with reduced light intensity vs placebo \\
\hline \multicolumn{2}{|l|}{ Outcomes } \\
\hline \multicolumn{2}{|l|}{ Starting date } \\
\hline \multicolumn{2}{|c|}{ Contact information Nic Gwatkin, Head of Marketing, Novartis Ophthalmics } \\
\hline \multicolumn{2}{|l|}{ Notes } \\
\hline Study & VIO \\
\hline Trial name or title & Visudyne therapy in Occult Phase III trial \\
\hline Participants & People with occult but no classic CNV due to AMD \\
\hline \multicolumn{2}{|l|}{ Interventions } \\
\hline \multicolumn{2}{|l|}{ Outcomes } \\
\hline \multicolumn{2}{|l|}{ Starting date } \\
\hline Contact information & Nic Gwatkin, Head of Marketing, Novartis Ophthalmics \\
\hline
\end{tabular}

\section{G R A P H S}

\section{Comparison 01. PHOTODYNAMIC THERAPY WITH VERTEPORFIN VERSUS PLACEBO}

Outcome title

01 Overall effect: $>=3$ lines lost at $12 \mathrm{mths}$

02 Overall effect: $>=3$ lines lost at 24 mths

03 Overall effect: $>=6$ lines lost at $12 \mathrm{mths}$

04 Overall effect: $>=6$ lines lost at 24 mths

05 Classic CNV subgroups: >=3 lines lost at $12 \mathrm{mths}$

06 Classic CNV subgroups: >=3 lines lost at $24 \mathrm{mths}$

\begin{abstract}
No. of No. of
\end{abstract} studies participants

Statistical method

Relative Risk (Fixed) 95\% CI

Relative Risk (Fixed) 95\% CI

Relative Risk (Fixed) 95\% CI

2948

Relative Risk (Fixed) 95\% CI

Relative Risk (Fixed) 95\% CI

Relative Risk (Fixed) 95\% CI
Effect size

$0.80[0.70,0.91]$

$0.77[0.69,0.87]$

Totals not selected

$0.62[0.50,0.76]$

Subtotals only

$0.77[0.69,0.87]$ 


\begin{tabular}{lcclc}
07 Adverse effects: Visual & 2 & 948 & Relative Risk (Fixed) 95\% CI & $1.61[1.24,2.09]$ \\
$\quad$ disturbance & & & & $2.54[1.50,4.31]$ \\
08 Adverse effects: Injection site & 2 & 948 & Odds Ratio (Fixed) 95\% CI & $8.40[1.11,63.58]$ \\
$\begin{array}{l}\text { 09 Adverse effects: Infusion- } \\
\text { related back pain }\end{array}$ & 2 & 948 & Odds Ratio (Fixed) 95\% CI \\
$\begin{array}{l}10 \text { Adverse effects: Allergic } \\
\text { reactions }\end{array}$ & 2 & 948 & Odds Ratio (Fixed) 95\% CI & $0.94[0.34,2.56]$ \\
$\begin{array}{l}11 \text { Adverse effects: Photosensitivity } \\
\text { reactions }\end{array}$ & 2 & 948 & Odds Ratio (Fixed) 95\% CI & $5.37[1.01,28.60]$ \\
\hline
\end{tabular}

\section{INDEX TERMS}

\section{Medical Subject Headings (MeSH)}

Glucose [therapeutic use]; Macular Degeneration [drug therapy]; Neovascularization, Pathologic; Photochemotherapy; Photosensitizing Agents [therapeutic use]; Porphyrins [therapeutic use]; Randomized Controlled Trials; Retinal Neovascularization [drug therapy]

Medical MeSH check words

Humans

\section{COVER SHEET}

Title

Authors

Contribution of author(s)

Issue protocol first published

Review first published

Date of most recent amendment

Date of most recent

SUBSTANTIVE amendment

What's New

Date new studies sought but none found

Date new studies found but not yet included/excluded

\section{Date new studies found and included/excluded}

Date authors' conclusions
section amended

\section{DOI}

Photodynamic therapy for neovascular age-related macular degeneration

Wormald R, Evans J, Smeeth L, Henshaw K

RW participated in protocol development, study selection and assessment and writing up of the original and update of the review.

JE participated in protocol development, study selection and assessment, data abstraction and entry and writing up of the original and update of the review.

LS participated in protocol development, study selection and assessment, data abstraction and entry and writing up of the original and update of the review.

$\mathrm{KH}$ abstracted data and entered data into RevMan for the update of the review and participated in the updating of the review text.

I

$2000 / 2$

21 September 2003

25 February 2003

Information not supplied by author

Information not supplied by author

Information not supplied by author

03 January 2003

30 May 2001

10.1002/14651858.CD002030

Photodynamic therapy for neovascular age-related macular degeneration (Review)

Copyright (2005 The Cochrane Collaboration. Published by John Wiley \& Sons, Ltd 

Cochrane Library number
CD002030
Editorial group
Cochrane Eyes and Vision Group
Editorial group code
HM-EYES

GRAPHS AND OTHER TABLES

Fig. I. Comparison 0I. PHOTODYNAMIC THERAPY WITH VERTEPORFIN VERSUS PLACEBO

01.01 Overall effect: >=3 lines lost at 12 mths

Review: Photodynamic therapy for neovascular age-related macular degeneration

Comparison: OI PHOTODYNAMIC THERAPY WITH VERTEPORFIN VERSUS PLACEBO

Outcome: 0 I Overall effect: $>=3$ lines lost at 12 mths

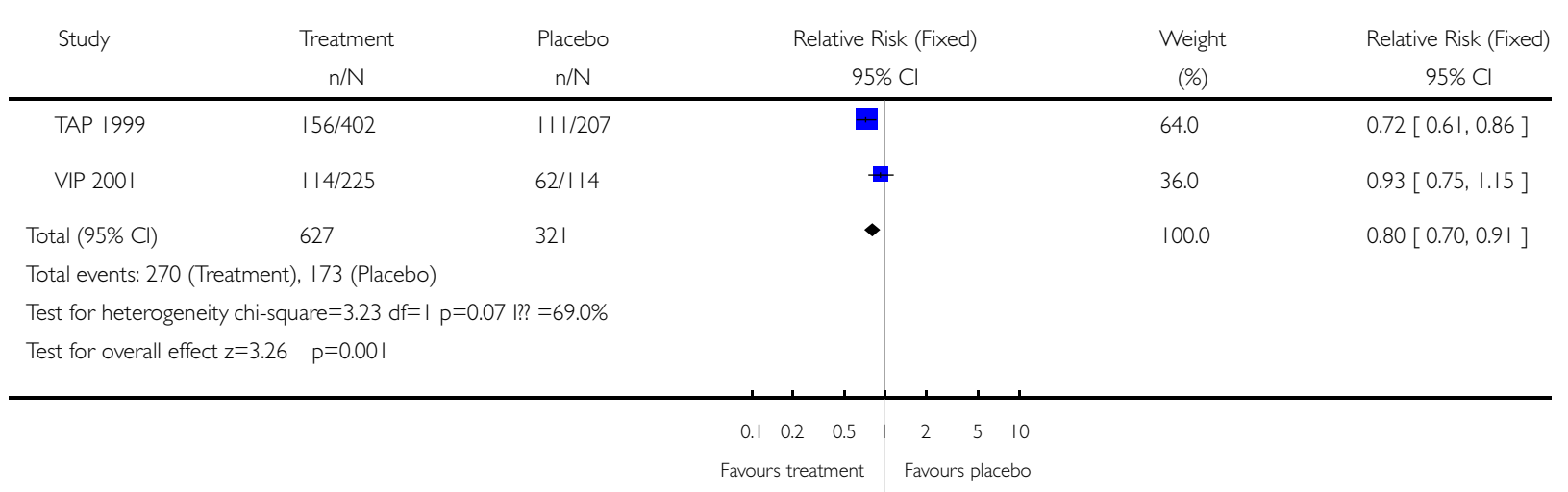

Fig. 2. Comparison 0I. PHOTODYNAMIC THERAPY WITH VERTEPORFIN VERSUS PLACEBO

01.02 Overall effect: >=3 lines lost at 24 mths

Review: Photodynamic therapy for neovascular age-related macular degeneration

Comparison: OI PHOTODYNAMIC THERAPY WITH VERTEPORFIN VERSUS PLACEBO

Outcome: 02 Overall effect: $>=3$ lines lost at 24 mths

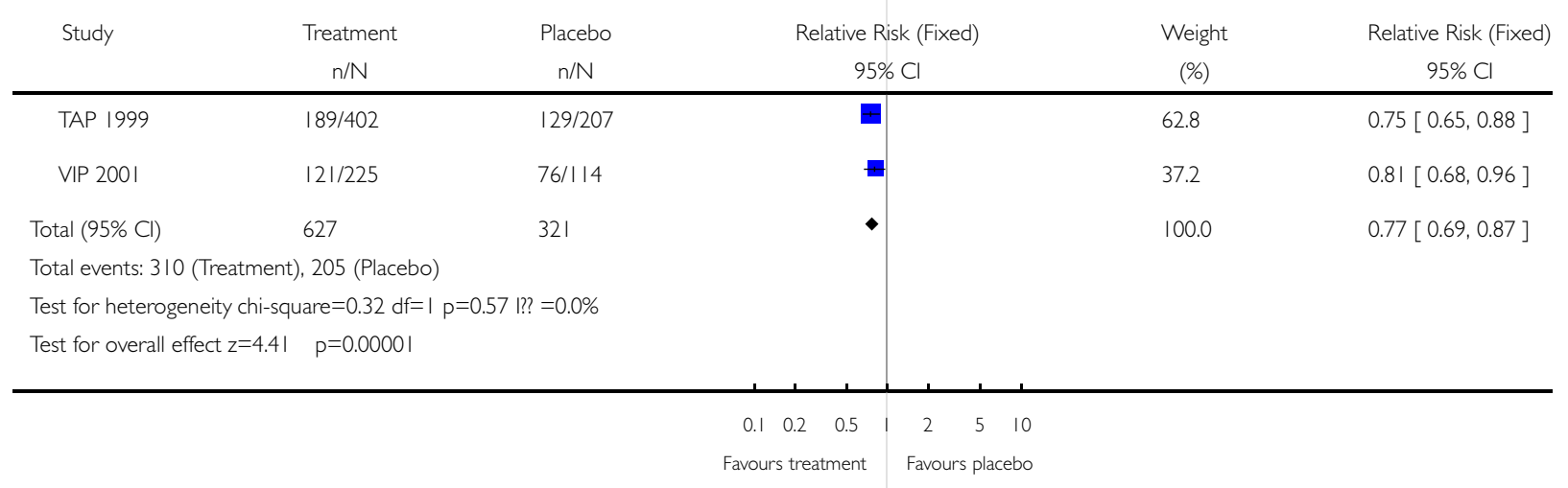

Photodynamic therapy for neovascular age-related macular degeneration (Review) 
Fig. 3. Comparison 0I. PHOTODYNAMIC THERAPY WITH VERTEPORFIN VERSUS PLACEBO

01.03 Overall effect: >=6 lines lost at 12 mths

Review: Photodynamic therapy for neovascular age-related macular degeneration

Comparison: 0 I PHOTODYNAMIC THERAPY WITH VERTEPORFIN VERSUS PLACEBO

Outcome: 03 Overall effect: $>=6$ lines lost at 12 mths

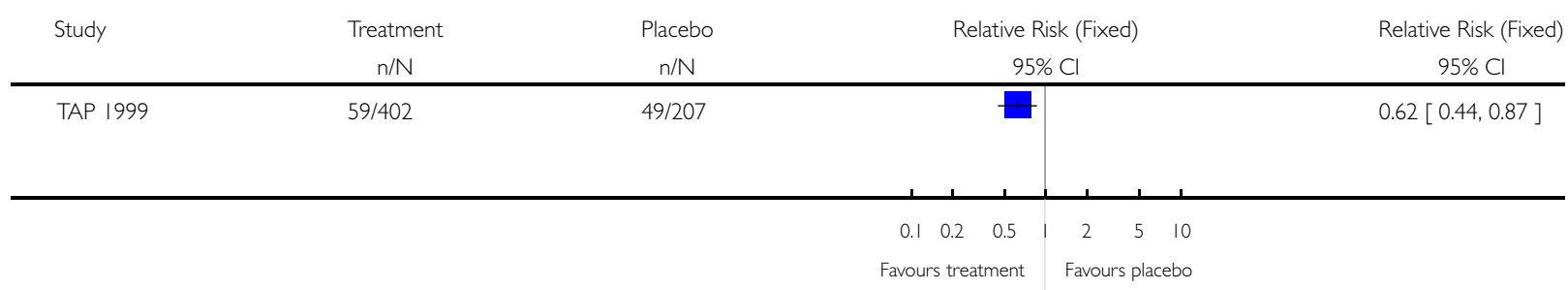

Fig. 4. Comparison OI. PHOTODYNAMIC THERAPY WITH VERTEPORFIN VERSUS PLACEBO

01.04 Overall effect: >=6 lines lost at 24 mths

Review: Photodynamic therapy for neovascular age-related macular degeneration

Comparison: 0 OI PHOTODYNAMIC THERAPY WITH VERTEPORFIN VERSUS PLACEBO

Outcome: 04 Overall effect: >=6 lines lost at 24 mths

\begin{tabular}{|c|c|c|c|c|c|}
\hline Study & $\begin{array}{c}\text { Treatment } \\
n / N\end{array}$ & $\begin{array}{c}\text { Placebo } \\
n / N\end{array}$ & $\begin{array}{c}\text { Relative Risk (Fixed) } \\
\qquad 95 \% \mathrm{Cl}\end{array}$ & $\begin{array}{c}\text { Weight } \\
(\%)\end{array}$ & $\begin{array}{c}\text { Relative Risk (Fixed) } \\
95 \% \mathrm{Cl}\end{array}$ \\
\hline TAP 1999 & $73 / 402$ & $62 / 207$ & \# & 53.3 & $0.61[0.45,0.81]$ \\
\hline VIP 2001 & $67 / 225$ & $54 / 114$ & + & 46.7 & $0.63[0.48,0.83]$ \\
\hline Total $(95 \% \mathrm{Cl})$ & 627 & 321 & $\bullet$ & 100.0 & $0.62[0.50,0.76]$ \\
\hline \multicolumn{6}{|c|}{ Total events: 140 (Treatment), I 16 (Placebo) } \\
\hline \multicolumn{6}{|c|}{ Test for heterogeneity chi-square $=0.03 \mathrm{df}=1 \mathrm{p}=0.86 \mathrm{l} ? \mathrm{?}=0.0 \%$} \\
\hline Test for overall & $p<0.0000$ I & & & & \\
\hline
\end{tabular}


Fig. 5. Comparison 0I. PHOTODYNAMIC THERAPY WITH VERTEPORFIN VERSUS PLACEBO

01.05 Classic CNV subgroups: >=3 lines lost at 12 mths

Review: Photodynamic therapy for neovascular age-related macular degeneration

Comparison: OI PHOTODYNAMIC THERAPY WITH VERTEPORFIN VERSUS PLACEBO

Outcome: 05 Classic CNV subgroups: >=3 lines lost at 12 mths

Study

Treatment

Placebo

Relative Risk (Fixed)

Weight

Relative Risk (Fixed)

$\mathrm{n} / \mathrm{N}$

$\mathrm{n} / \mathrm{N}$

OI No classic CNV

TAP 1999

$14 / 38$

$13 / 19$

Subtotal $(95 \% \mathrm{Cl})$

38

19

Total events: 14 (Treatment), I 3 (Placebo)

Test for heterogeneity: not applicable

Test for overall effect $z=2.35 \quad p=0.02$

02 Classic CNV $>0$ to $<50 \%$

TAP 1999

$89 / 202$

$46 / 103$

Subtotal $(95 \% \mathrm{Cl})$

202

103

Total events: 89 (Treatment), 46 (Placebo)

Test for heterogeneity: not applicable

Test for overall effect $z=0.10 \quad p=0.9$

03 Classic CNV > 50\% (predominantly classic)

$\begin{array}{lrl}\text { TAP } 1999 & 52 / 159 & 51 / 84\end{array}$

Subtotal $(95 \% \mathrm{Cl})$

159

84

Total events: 52 (Treatment), 5 I (Placebo)

Test for heterogeneity: not applicable

Test for overall effect $z=4.31 \quad p=0.00002$

(\%)

95\% Cl

$95 \% \mathrm{C}$

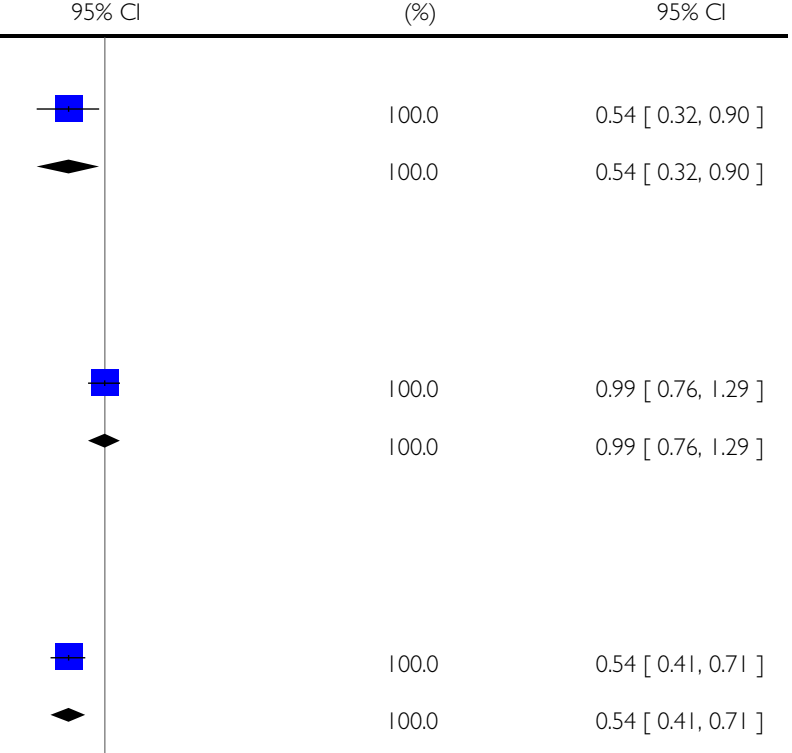


Fig. 6. Comparison 0I. PHOTODYNAMIC THERAPY WITH VERTEPORFIN VERSUS PLACEBO

01.06 Classic CNV subgroups: >=3 lines lost at 24 mths

Review: Photodynamic therapy for neovascular age-related macular degeneration

Comparison: $\quad$ OI PHOTODYNAMIC THERAPY WITH VERTEPORFIN VERSUS PLACEBO

Outcome: 06 Classic CNV subgroups: >=3 lines lost at 24 mths

$\begin{array}{llll}\text { Study } & \text { Treatment } & \text { Placebo } & \text { Relative Risk (Fixed) Weight }\end{array}$

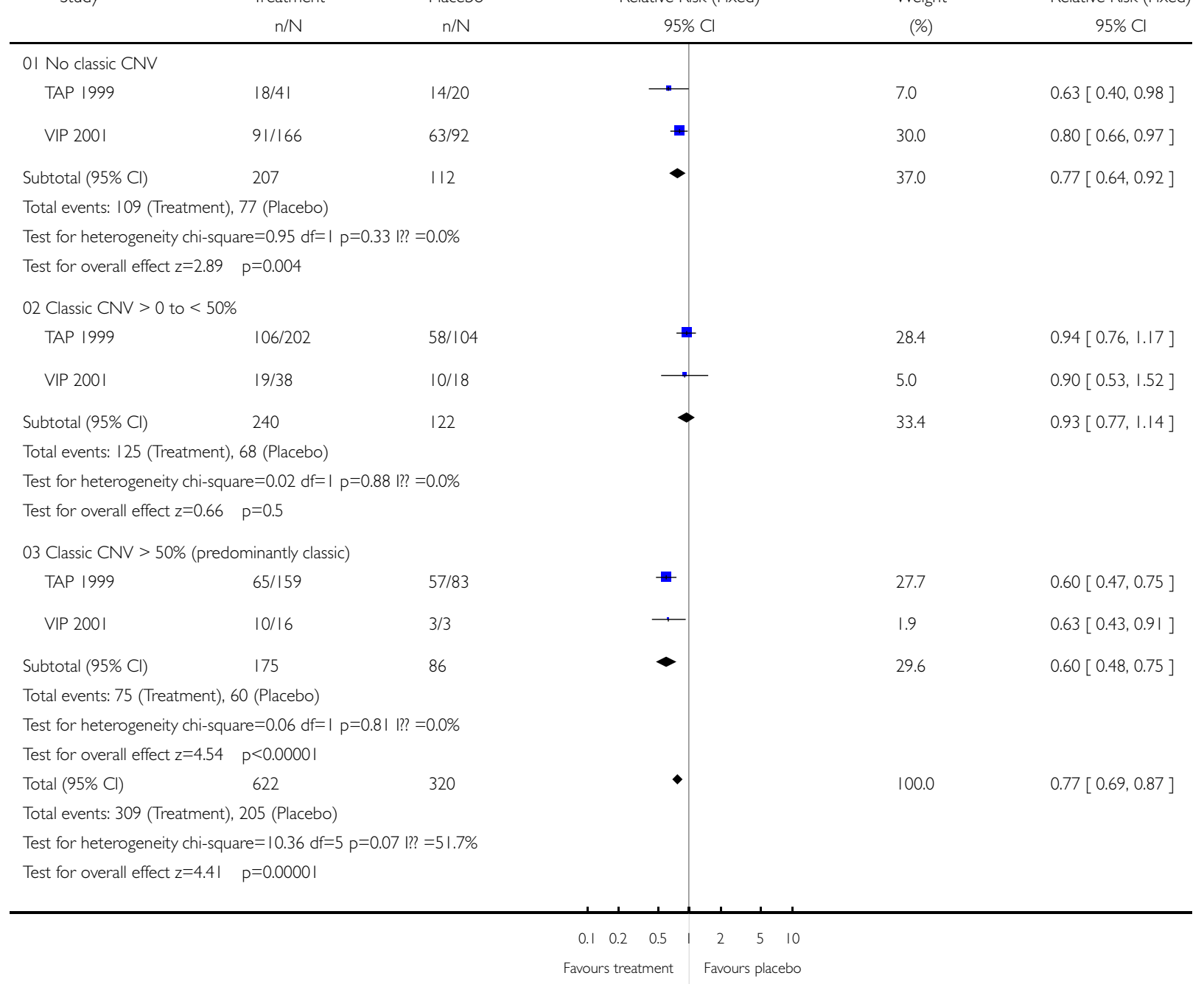

Photodynamic therapy for neovascular age-related macular degeneration (Review) 
Fig. 7. Comparison OI. PHOTODYNAMIC THERAPY WITH VERTEPORFIN VERSUS PLACEBO

01.07 Adverse effects: Visual disturbance

Review: Photodynamic therapy for neovascular age-related macular degeneration

Comparison: OI PHOTODYNAMIC THERAPY WITH VERTEPORFIN VERSUS PLACEBO

Outcome: 07 Adverse effects: Visual disturbance

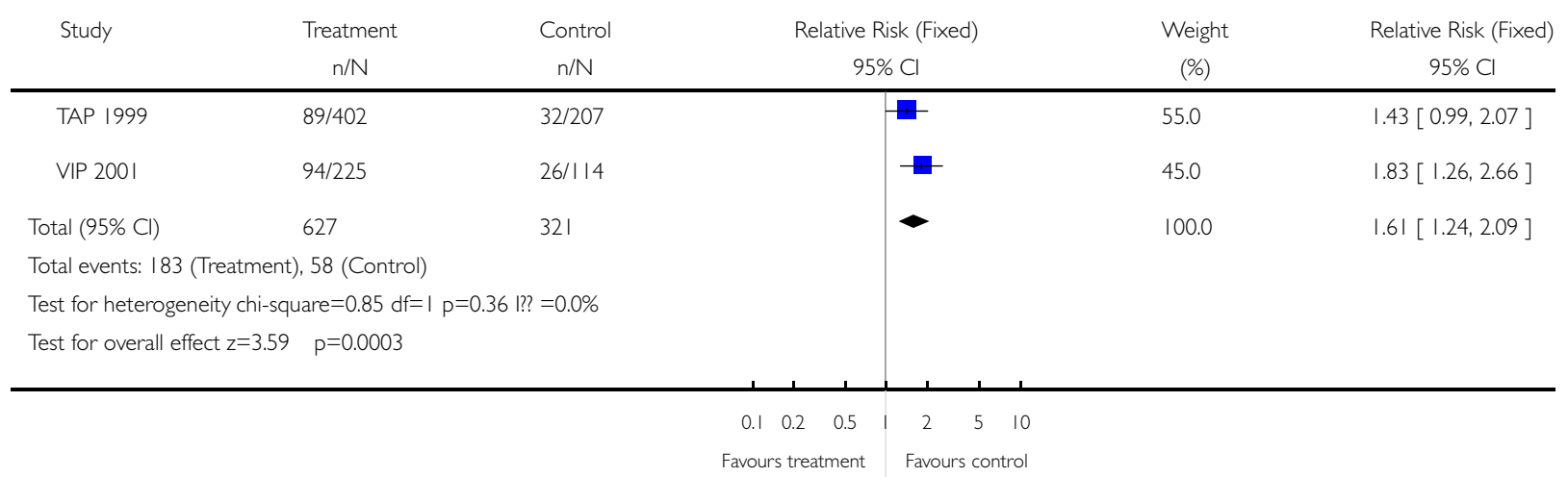

Fig. 8. Comparison OI. PHOTODYNAMIC THERAPY WITH VERTEPORFIN VERSUS PLACEBO

0 I.08 Adverse effects: Injection site

Review: Photodynamic therapy for neovascular age-related macular degeneration

Comparison: OI PHOTODYNAMIC THERAPY WITH VERTEPORFIN VERSUS PLACEBO

Outcome: 08 Adverse effects: Injection site

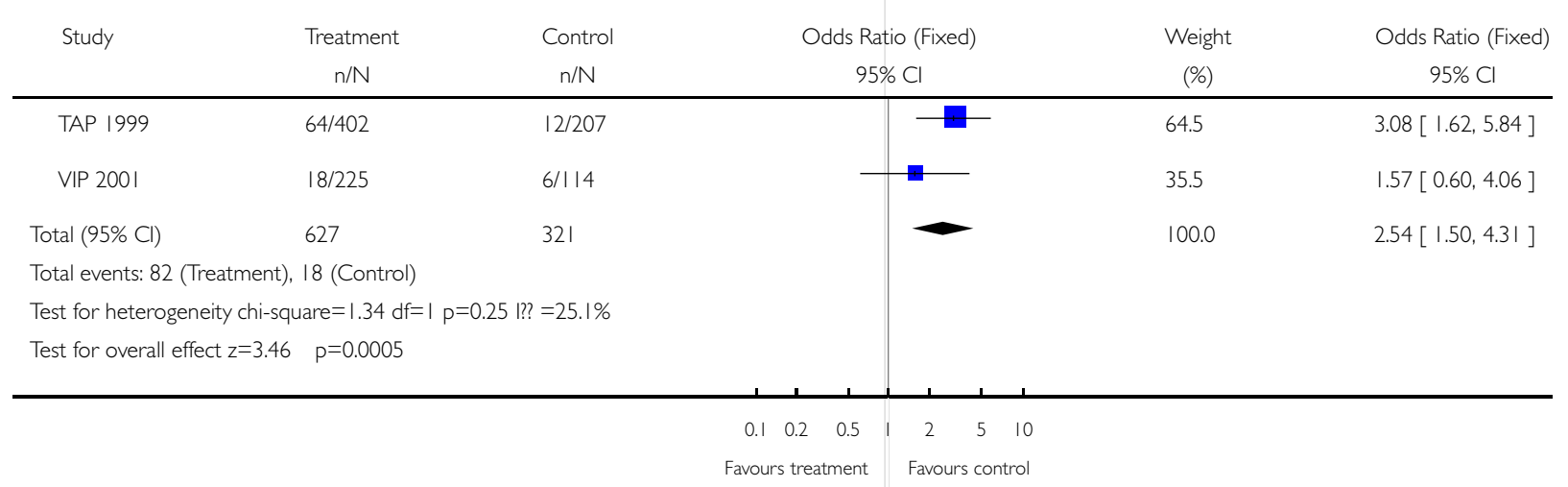


Fig. 9. Comparison 0I. PHOTODYNAMIC THERAPY WITH VERTEPORFIN VERSUS PLACEBO

0I.09 Adverse effects: Infusion-related back pain

Review: Photodynamic therapy for neovascular age-related macular degeneration

Comparison: 0 I PHOTODYNAMIC THERAPY WITH VERTEPORFIN VERSUS PLACEBO

Outcome: 09 Adverse effects: Infusion-related back pain

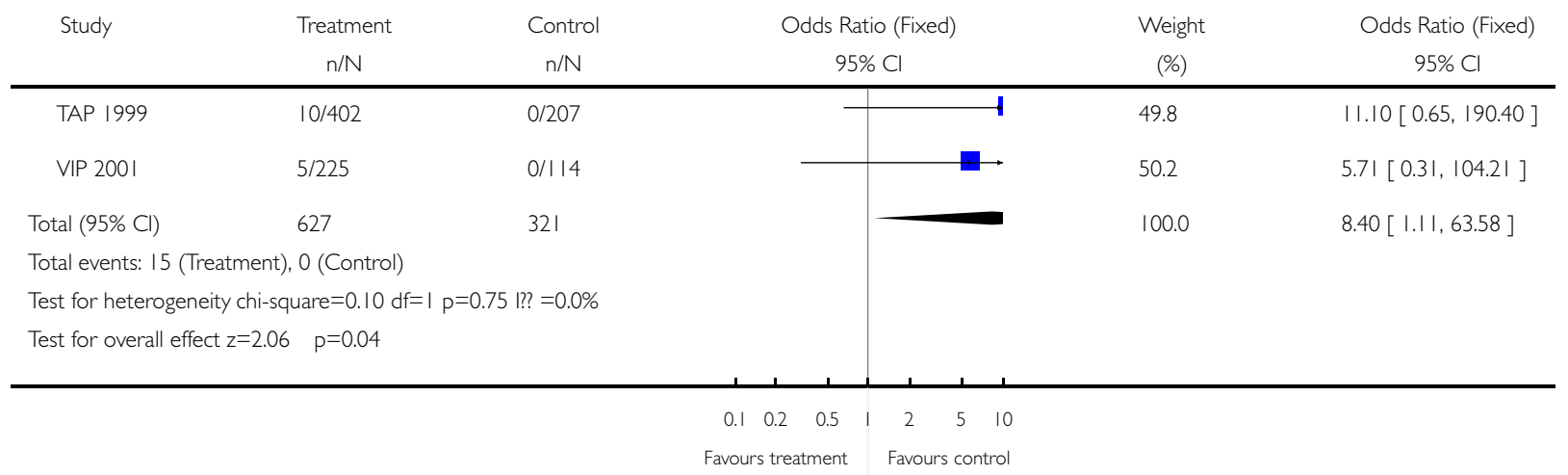

Fig. 10. Comparison 0I. PHOTODYNAMIC THERAPY WITH VERTEPORFIN VERSUS PLACEBO

0I.10 Adverse effects: Allergic reactions

Review: Photodynamic therapy for neovascular age-related macular degeneration

Comparison: OI PHOTODYNAMIC THERAPY WITH VERTEPORFIN VERSUS PLACEBO

Outcome: 10 Adverse effects: Allergic reactions

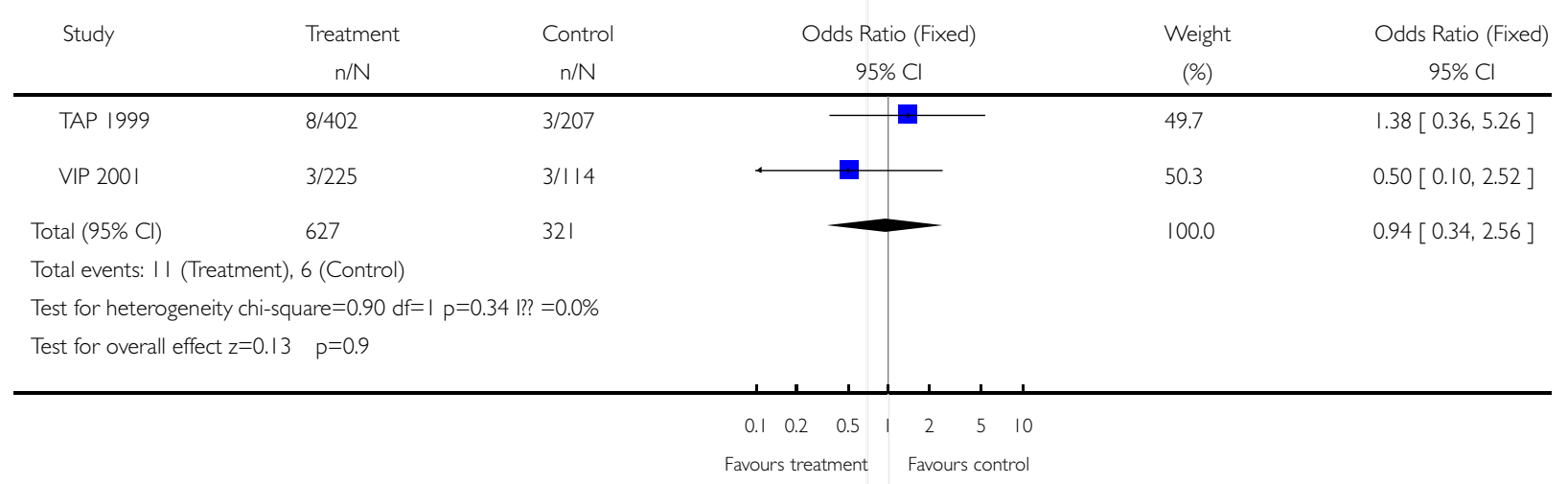


Fig. II. Comparison 0I. PHOTODYNAMIC THERAPY WITH VERTEPORFIN VERSUS PLACEBO

0I.I I Adverse effects: Photosensitivity reactions

Review: Photodynamic therapy for neovascular age-related macular degeneration

Comparison: OI PHOTODYNAMIC THERAPY WITH VERTEPORFIN VERSUS PLACEBO

Outcome: II Adverse effects: Photosensitivity reactions

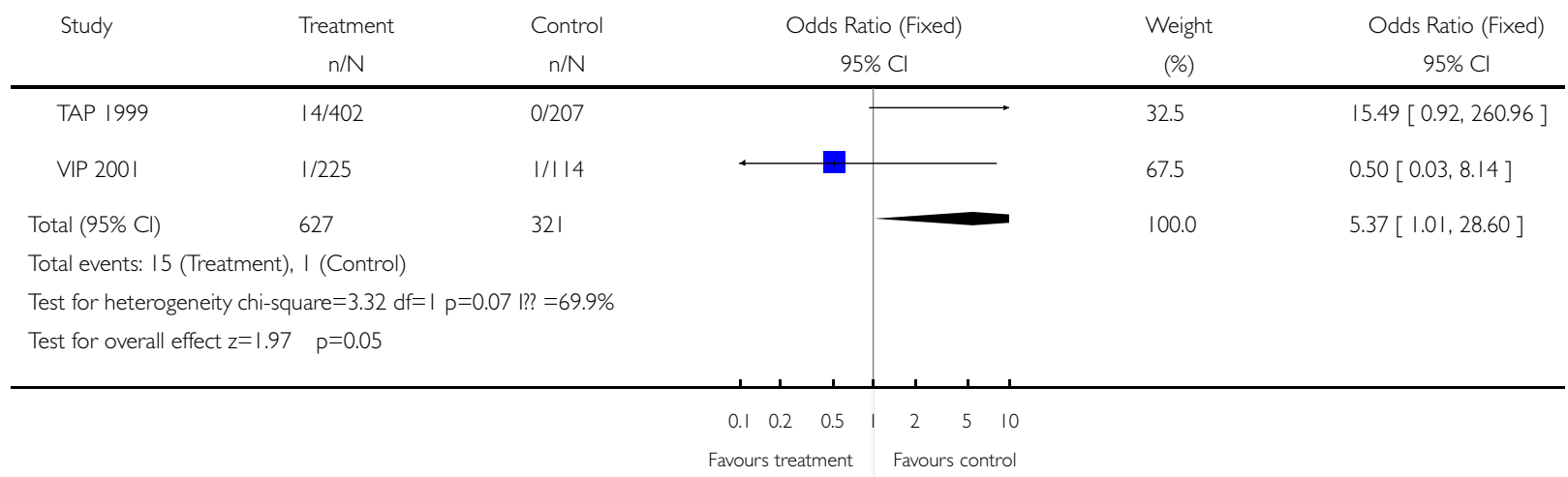

